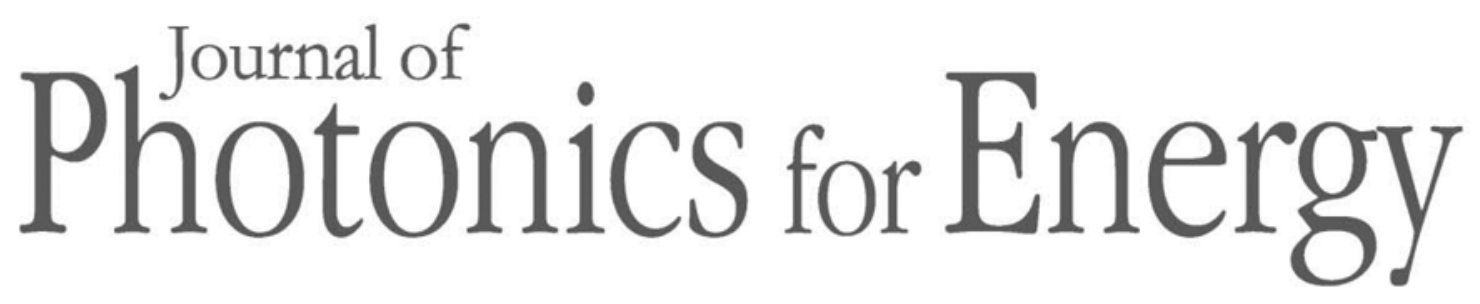

PhotonicsforEnergy.SPIEDigitalLibrary.org

\title{
Fullerene-based Schottky-junction organic solar cells: a brief review
}

Sibi Sutty

Graeme Williams

Hany Aziz 


\title{
Fullerene-based Schottky-junction organic solar cells: a brief review
}

\author{
Sibi Sutty,* Graeme Williams, and Hany Aziz \\ University of Waterloo, Department of Electrical and Computer Engineering, \\ 200 University Avenue West, Waterloo, Ontario N2L 3G1, Canada
}

\begin{abstract}
Recent advances in fullerene-based Schottky organic solar cells (OSCs) are presented, with a focus on the current understanding of device physics. Fullerene-based Schottky OSCs attain high open-circuit voltages due to the n-type Schottky junction formed between fullerene and an adjacent high work function anode. Small concentrations of donor material doped into the fullerene matrix serve as efficient exciton dissociation and hole transport agents that can substantially bolster short-circuit currents and fill factors. As a consequence, fullerene-based Schottky OSCs have been demonstrated to provide some of the highest-performance vacuum-deposited small molecule OSCs, with power conversion efficiencies up to $8.1 \%$. Fullerene-based Schottky OSCs constructed using different donor materials and varying cathode buffer layers, as studied by a number of different research groups, are presented. To elucidate the differences between Schottky OSCs and more traditional bulk-heterojunction OSCs, we discuss the photophysics of fullerenes, the role of the donor material, and charge transport in low donor concentration active layers. Fullerene-based Schottky OSCs possess considerable advantages because they can reach high efficiencies with a simple structure using readily available and cost-effective materials. The impact and applicability of the Schottky device architecture on the field of organic photovoltaics at large are discussed. (c) The Authors. Published by SPIE under a Creative Commons Attribution 3.0 Unported License. Distribution or reproduction of this work in whole or in part requires full attribution of the original publication, including its DOI. [DOI: 10.1117/1.JPE.4.040999]
\end{abstract}

Keywords: organic photovoltaics; Schottky junction; device structure; low donor concentration; small molecule; bulk heterojunction.

Paper 14011V received Mar. 5, 2014; revised manuscript received Apr. 3, 2014; accepted for publication Apr. 7, 2014; published online May 7, 2014.

\section{Introduction}

The performance of organic solar cells (OSCs) has been continuously improving due to the concurrent development of new organic materials and device structures. ${ }^{1-5}$ In this review, the development of the emerging and highly promising fullerene-based Schottky OSC device architecture is presented. This device architecture has been the subject of intense research in the past 2 years due to its simplicity, use of easily available (and in many cases cost-effective) materials, and very high power conversion efficiencies (PCEs). The objective of this review is to present current understanding of the device physics of fullerene-based Schottky junction OSCs and highlight the progress made in improving the performance of this device architecture. In Sec. 2, we report on recent progress in fullerene-based Schottky junction OSCs, with a comprehensive analysis of the reports in the literature that employ this particular device structure. Specific details regarding the device physics, especially the reasons behind the PCE values obtained using this relatively unstudied device architecture, are discussed in Sec. 3.

In order to better understand the appeal of the fullerene-based Schottky OSC, it is worthwhile to briefly examine the historical developments in OSC device architecture to date. Some of the earliest OSCs were fabricated by sandwiching p-type organic semiconductors in between metal electrodes, ${ }^{6}$ with photovoltaic properties granted by the Schottky contact formed between the

*Address all correspondence to: Sibi Sutty, E-mail: sbssutty@uwaterloo.ca 
p-type organic semiconductor and the low work-function electrode. The operation of these devices was based upon the formation of a rectifying metal-insulator-semiconductor junction between the p-type organic material and the low work-function metal. While these early OSCs offered high open-circuit voltages $\left(\mathrm{V}_{\mathrm{oc}}\right)$ of up to $1 \mathrm{~V}$, their overall performance was quite poor, with PCE values ranging from less than $10^{-4} \%$ to $0.7 \%$, due to extremely low short-circuit current $\left(\mathrm{J}_{\mathrm{sc}}\right)$ and fill factors $(\mathrm{FF})$. The, generally poor performance was caused by the poor exciton dissociation properties of the device architecture, essentially limited to field-dependent dissociation of excitons immediately next to the organic semiconductor/ metal interface. In 1986, Tang published a two-layer OSC device structure, which relied on the formation of a heterojunction between a p-type (or donor) and a n-type (or acceptor) organic semiconductor, ${ }^{7}$ with the structure: indium tin oxide (ITO)/copper phthalocyanine (CuPc)/perylene tetracarboxylic derivative (PV)/Ag. This planar heterojunction (PHJ) structure naturally provided substantial gains in photocurrent due to the efficient dissociation of excitons at the $\mathrm{CuPc} / \mathrm{PV}$ interface. However, the $\mathrm{V}_{\text {oc }}$ was much lower for the two-layer device $(<0.45 \mathrm{~V})$ than the previous p-type Schottky OSCs because it was no longer set by the organic semiconductor/metal interface, but rather by the organic/organic heterojunction.

The impressive performance of the two-layer OSC led to a substantial increase in research activity in the field of organic photovoltaics in general. ${ }^{1,2}$ The next major shift in OSC device architecture occurred when researchers mixed the donor and acceptor materials together to form the bulk heterojunction (BHJ). ${ }^{8-12}$ The charge-generation capabilities of the BHJ was much higher than the two-layer OSC, because the interfacial area between the donor and acceptor material was increased substantially. However, as with the PHJ, the $\mathrm{V}_{\mathrm{oc}}$ of the BHJ was dictated by organic/organic interface, essentially limited by the energy level difference between the donor's highest occupied molecular orbital (HOMO) and the acceptor's lowest unoccupied molecular orbital (LUMO). The commonly accepted model for the $\mathrm{V}_{\mathrm{oc}}$ in either the PHJ or BHJ is: $\mathrm{V}_{\mathrm{oc}}=1 / e\left(\left|\mathrm{E}_{\mathrm{HOMO}}^{\text {Donor }}\right|-\left|\mathrm{E}_{\mathrm{LUMO}}^{\text {Acceptor }}\right|\right)-0.3 \mathrm{~V}$, where the $0.3 \mathrm{~V}$ factor represents energetic losses within the material or at the organic-electrode interfaces. ${ }^{2-4}$ Coupled with the introduction of highly absorbing donor materials ${ }^{2,3}$ and efficient acceptor materials, such as fullerenes, ${ }^{13,14}$ the establishment of the BHJ architecture allowed for rapid improvements in PCE.

However, since the development of the BHJ, interest in novel device architectures has slowed, with most new structures employing a BHJ mixed layer in combination with other photoactive, charge transport, or charge extraction layers. Noting that OSCs with the BHJ architecture generally have lower FF values due to poor charge transport, several researchers employed neat layers of donor and acceptor materials to border the BHJ layer., ${ }^{3,8}$ Doping the neat donor and acceptor layers to increase the free-carrier concentration and hence control the Fermi level was demonstrated as a powerful approach to improve the OSC FF. ${ }^{15}$ This particular OSC structure resembled that of an inorganic p-i-n solar cell, with the majority of charge carrier generation occurring in the thin BHJ " $i$ " layer. Single junction p-i-n OSCs have been demonstrated in the literature to reach efficiencies of 4.0\%-6.0\%, ${ }^{3,16}$ while companies such as Heliatek GmbH (Dresden, Germany) have shown these p-i-n OSCs in the tandem configuration to be capable of reaching PCE values over $10 \% .{ }^{17}$

The Schottky OSC architecture has witnessed a resurgence in popularity in recent years due to its notably high performance when fullerenes, instead of p-type organic semiconductors, are used as the principal photoactive material and to form the Schottky contact. The device structure of fullerene-based Schottky OSCs is surprisingly simple, with only one donor-acceptor mixed active layer situated adjacent to a high work function anode. Unlike standard BHJ OSCs, where the concentration of the donor and acceptor species was roughly equal, fullerene-based Schottky junction OSCs feature a donor-acceptor mixed layer with very high (80\%-95\%) fullerene acceptor concentrations. In spite of this simple design and use of readily available materials, the efficiency of fullerene-based Schottky OSCs has been demonstrated to exceed $8.0 \%,{ }^{18}$ which is higher than the best reported single junction p-i-n cells. The development of the fullerene-based Schottky junction OSC is important because: (1) in addition to the planar junction, BHJ and p-i-n OSCs, it represents an alternative and novel device structure capable of achieving high efficiencies, (2) it highlights the photoactive properties of fullerene acceptors and sheds light on the device physics of fullerene-rich OSCs, and (3) it shows how Schottky junction interfaces can improve OSC performance by having the $\mathrm{V}_{\mathrm{oc}}$ determined by the Schottky barrier 
instead of the commonly accepted $\mathrm{HOMO}_{\text {donor }}-\mathrm{LUMO}_{\text {acceptor }}$ energy level difference. A brief review of the development of fullerene-based Schottky junction OSCs to date is now warranted in order to understand the factors that have led to the impressive performance of this device architecture.

In Sec. 2 below, we now focus on these high-efficiency reports in the literature and put them in the context of the first reports of the $\mathrm{MoO}_{3} / \mathrm{C}_{60}$ Schottky OSCs discovered only a few years past.

\section{Initial Reports and Recent Progress}

The first fullerene-based Schottky OSC was introduced by Zhang et al. in 2010 with the device structure: $\mathrm{ITO} / \mathrm{MoO}_{3} / \mathrm{C}_{60} /$ bathophenanthroline (Bphen) $/ \mathrm{LiF} / \mathrm{Al} .{ }^{19}$ ITO $/ \mathrm{MoO}_{3}$ was used as the high work function anode, and $\mathrm{C}_{60}$ was the sole photoactive material in the device. While the visible absorption of $\mathrm{C}_{60}$ is quite weak, the best performing neat- $\mathrm{C}_{60}$ Schottky OSCs, reported later in 2011 by Zhang et al, exceeded expectations with a $\mathrm{J}_{\mathrm{sc}}$ of $1.6 \mathrm{~mA} / \mathrm{cm}^{2}, \mathrm{~V}_{\mathrm{oc}}$ of $1.3 \mathrm{~V}$, FF of $31 \%$, and PCE of $0.65 \% .{ }^{20}$ The origin of the high $\mathrm{V}_{\mathrm{oc}}$ and $\mathrm{J}_{\mathrm{sc}}$ was attributed to the formation of a Schottky junction at the ITO/ $\mathrm{MoO}_{3} / \mathrm{C}_{60}$ interface. ${ }^{19}$ In contrast, the $\mathrm{V}_{\mathrm{oc}}$ of a simple ITO/C $\mathrm{C}_{60}$ cell was reported to be $0.4 \mathrm{~V} .{ }^{20}$ Ultraviolet photoelectron spectroscopy (UPS) and inverse photoemission spectroscopy (IPES) were used to study the ITO $/ \mathrm{MoO}_{3} / \mathrm{C}_{60}$ interface. A strong increase in the work function of ITO, from approximately 5.78 to $6.8 \mathrm{eV}$, was reported upon the deposition of the $\mathrm{MoO}_{3}$ buffer layer. The increase in the work function of the ITO/ $\mathrm{MoO}_{3}$ electrode was attributed to the formation of a $1.02-\mathrm{eV}$ interface dipole at the ITO/ $\mathrm{MoO}_{3}$ interface. A significant interfacial dipole was not measured at the $\mathrm{MoO}_{3} / \mathrm{C}_{60}$ interface. The high work function of the ITO/MoO 3 anode causes charge transfer (CT) from $\mathrm{C}_{60}$ to the $\mathrm{MoO}_{3}$ resulting in the formation of a $\mathrm{C}_{60}{ }^{+}$space charge layer. ${ }^{21}$ By employing in situ measurements, the researchers noted that the energy levels of $\mathrm{C}_{60}$ gradually relaxed to their bulk value as the $\mathrm{C}_{60}$ layer thickness was increased, indicating the presence of band bending within the $\mathrm{C}_{60}$ layer (determined to extend approximately $40 \mathrm{~nm}$ away from the $\mathrm{ITO} / \mathrm{MoO}_{3}$ anode). ${ }^{19,21}$ Figure 1 shows the energy level diagram of the ITO/ $\mathrm{MoO}_{3} / \mathrm{C}_{60}$ interface inferred using UPS and IPES data. ${ }^{21}$

When the fullerene-based Schottky OSCs were doped with low concentrations of donor material, Zhang et al. observed that the OSC performance increased considerably. ${ }^{20}$ Specifically, upon the addition of 5\% of 1,1-bis-(4-bis(4-methyl-phenyl)-amino-phenyl)-cyclohexane (TAPC) as a donor material into the $\mathrm{C}_{60}$ matrix, the $\mathrm{J}_{\mathrm{sc}}$ and $\mathrm{FF}$ increased dramatically while the high $\mathrm{V}_{\mathrm{oc}}$ was largely unaffected. As a consequence, the PCE of the TAPC-doped $\mathrm{C}_{60}$ Schottky OSC increased over fourfold from the cells composed of neat $\mathrm{C}_{60}$. Furthermore, the

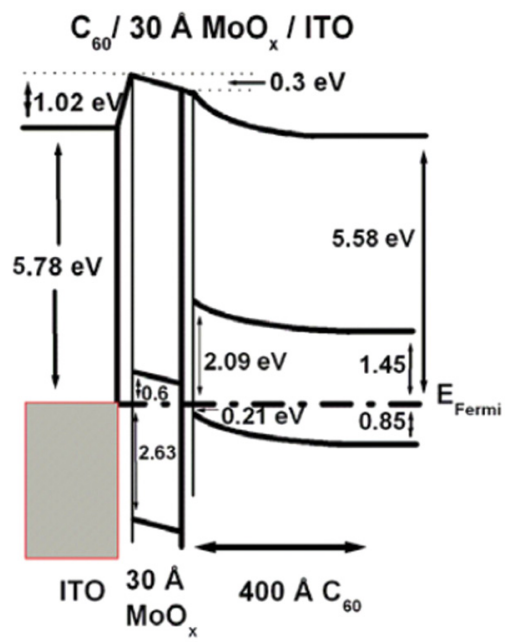

Fig. 1 Energy level diagram of the ITO/ $\mathrm{MoO}_{3} / \mathrm{C}_{60}$ interface as determined using UPS and IPES. Reproduced with permission from Ref. 21. Copyright (C) 2011 by Elsevier B.V. 


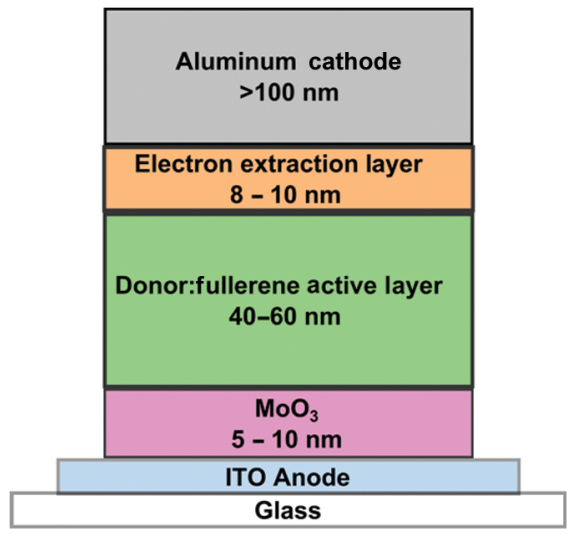

Fig. 2 General structure of a Schottky junction OSC with typical thicknesses of layers reported in literature.

researchers showed that using $\mathrm{C}_{70}$ instead of $\mathrm{C}_{60}$ increased the performance of the OSCs even further, due to its much stronger visible absorption. For reference, Fig. 2 shows the general structure of a fullerene-based Schottky junction OSC with typical thicknesses of layers reported in the literature. Zhang et al. used BPhen/LiF as an electron extraction layer and TAPC: $\mathrm{C}_{60}$ as the donor-fullerene active layer.

In their initial work, Zhang et al. noted that the $\mathrm{V}_{\mathrm{oc}}$ of the TAPC: $\mathrm{C}_{60}$ active layer OSC was heavily dependent on the mixing ratio of the two species. Neat $\mathrm{C}_{60}$ Schottky OSCs demonstrated $\mathrm{a} \mathrm{V}_{\mathrm{oc}}$ of $1.33 \mathrm{~V}$. Upon the addition of $1.2 \%$ of TAPC, the $\mathrm{V}_{\mathrm{oc}}$ decreased to $1.02 \mathrm{~V}$. Further addition of TAPC donor decreased the $\mathrm{V}_{\text {oc }}$ even further up to $0.74 \mathrm{~V}$ (at a TAPC concentration of $50 \%$ ). Zhang et al. attributed the decrease in the $\mathrm{V}_{\mathrm{oc}}$ to the TAPC HOMO energy level becoming shallower, and hence reducing the $\mathrm{HOMO}_{\mathrm{TAPC}}-\mathrm{LUMO}_{\mathrm{C} 60}$ difference, as the TAPC concentration increased in the mixed layer. ${ }^{20}$ However, at low concentrations, they noted that the $\mathrm{V}_{\mathrm{oc}}$ of the TAPC doped Schottky OSC was characteristic to the Schottky junction formed at the ITO $/ \mathrm{MoO}_{3} / \mathrm{C}_{60}$ interface instead of the $\mathrm{HOMO}_{\text {donor }}-\mathrm{LUMO}_{\text {acceptor }}$ offset. ${ }^{20}$ When the mixing ratio of the donor-acceptor species is varied in a p-i-n type OSC, recent reports have shown that the $\mathrm{V}_{\mathrm{oc}}$ variation is usually less than $\pm 100 \mathrm{mV}$, indicating that the impact of varying HOMO energy levels as a function of mixing ratio is minimal. ${ }^{22,23}$ This lends more evidence to the fact that the $\mathrm{V}_{\mathrm{oc}}$ is determined by the band bending at the ITO/ $\mathrm{MoO}_{3} / \mathrm{C}_{60}$ interface in a Schottky junction OSC. With regard to the enhanced $\mathrm{J}_{\mathrm{sc}}$ upon the addition of the donor material, Zhang et. al suggested that it was due to an increase in exciton dissociation efficiency in the $\mathrm{C}_{60}$ matrix.

Most strikingly, Zhang et al. observed only small differences in performance when donors,

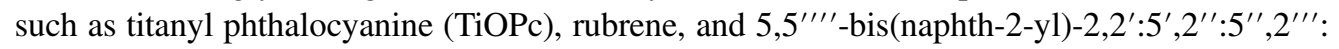
$5^{\prime \prime \prime}, 2^{\prime \prime \prime \prime}$ quinquethiophene (NaT5), were used instead of TAPC in 5\% concentration mixtures with $\mathrm{C}_{60} \cdot{ }^{20}$ The $\mathrm{J}_{\mathrm{sc}}$ for the $5 \%$ donor- $\mathrm{C}_{60}$ active layers ranged from 5 to $6 \mathrm{~mA} / \mathrm{cm}^{2}$ and the $\mathrm{V}_{\mathrm{oc}}$ varied from 0.9 to $1.0 \mathrm{~V}$. Considering that each of these donor materials possesses different HOMO and LUMO energy levels, this particular experiment provided further critical evidence that the $\mathrm{V}_{\mathrm{oc}}$ of the donor-doped Schottky OSC was not determined by the $\mathrm{HOMO}_{\text {donor }}-$ $\mathrm{LUMO}_{\text {acceptor }}$ offset, but rather by the band bending at the ITO/ $\mathrm{MoO}_{3} / \mathrm{C}_{60}$ interface. ${ }^{20}$ As a result, the $\mathrm{V}_{\mathrm{oc}}$ was suggested to be critically dependent on the presence of the $\mathrm{MoO}_{3}$ anode buffer layer. Future work has shown that increasing the work function of the ITO using $\mathrm{CF}_{4}: \mathrm{O}_{2}$ or $\mathrm{O}_{2}$ plasma treatments also allows for the formation of the band bending region in $\mathrm{C}_{60} \cdot{ }^{24}$ Perhaps most critically, Zhang et al. demonstrated a high-efficiency donor-doped Schottky OSC with a $60 \mathrm{~nm}$ TAPC $(5 \%): \mathrm{C}_{70}(95 \%)$ active layer, which achieved a $\mathrm{J}_{\mathrm{sc}}$ of $11.43 \mathrm{~mA} / \mathrm{cm}^{2}, \mathrm{~V}_{\mathrm{oc}}$ of $0.91 \mathrm{~V}, \mathrm{FF}$ of $50.2 \%$, and a PCE of $5.23 \%$. At the time of publication, this was one of the highest single-cell efficiencies for vacuum-deposited small molecule OSCs.

Following the seminal works of Zhang et al., several groups have utilized donor-doped fullerene heavy active layers adjacent to an ITO/ $\mathrm{MoO}_{3}$ anode to fabricate Schottky OSCs. Tables 1 and 2 provide a performance summary of the vacuum-deposited Schottky OSCs reported in the literature to date (for $\mathrm{C}_{60^{-}}$and $\mathrm{C}_{70^{-}}$-based Schottky OSCs, respectively). The 
Table 1 Performance summary of $\mathrm{C}_{60}$-based Schottky OSCs reported in the literature.

\begin{tabular}{|c|c|c|c|c|c|c|}
\hline Donor & $\begin{array}{c}\text { Donor } \\
\text { doping } \\
{[\%]}\end{array}$ & $\begin{array}{c}J_{s c} \\
{\left[\mathrm{~mA} \mathrm{~cm}^{-2}\right]}\end{array}$ & $\mathrm{V}_{\mathrm{oc}}[\mathrm{V}]$ & $\begin{array}{l}\mathrm{FF} \\
{[\%]}\end{array}$ & $\begin{array}{l}\text { PCE } \\
{[\%]}\end{array}$ & References \\
\hline - & 0 & 1.2 & 1.2 & 32 & 0.42 & 25 \\
\hline Boron subphthalocyanine chloride (SubPc) & 20 & 7.9 & 1.07 & 44 & 3.7 & 26 \\
\hline SubPc & 25 & 5.60 & 1.1 & 45 & 2.7 & 27 \\
\hline Chloro-aluminum phthalocyanine (CIAIPc) & 5 & 5.6 & 1.01 & 39 & 2.1 & 28 \\
\hline CIAIPc & 25 & 6.27 & 0.87 & 37 & 2.0 & 27 \\
\hline Chloro-indium phthalocyanine (CllnPc) & 25 & 6.68 & 0.92 & 40 & 2.47 & 25 \\
\hline Chloro-gallium phthalocyanine (CIGaPc) & 12.5 & 5.76 & 0.96 & 42 & 2.3 & 27 \\
\hline Phthalocyanine $\left(\mathrm{H}_{2} \mathrm{Pc}\right)$ & 12.5 & 5.68 & 0.84 & 41 & 2.0 & 27 \\
\hline Titanyl phthalocyanine (TiOPc) & 12.5 & 4.67 & 0.91 & 35 & 1.5 & 27 \\
\hline $\begin{array}{l}\text { 4,4',4"-tris(N-3-methylphenyl-N-phenylamine) } \\
\text { triphenyl-amine (m-MTDATA) }\end{array}$ & 2 & 2.1 & 0.87 & 39 & 0.71 & 29 \\
\hline 4,4,4-Tris(N-carbazolyl-triphenyl amine) (TCTA) & 5 & 5.2 & 0.91 & 40 & 1.91 & 29 \\
\hline 4,4'-bis(carbazol-9- yl)biphenyl (CBP) & 10 & 1.1 & 1.19 & 31 & 0.41 & 25 \\
\hline Tris(8-hydroxy-quinolinato)aluminum (Alq3) & 10 & 2.4 & 0.73 & 34 & 0.61 & 25 \\
\hline $\begin{array}{l}\text { 4-(dicyanomethylene)-2-tert-butyl-6-(1,1,7,7- } \\
\text { tetramethyljulolidin-4-yl-vinyl)-4H-pyran } \\
\text { (DCJTB) }\end{array}$ & 10 & 2.9 & 0.61 & 34 & 0.61 & 25 \\
\hline $\begin{array}{l}\text { N,NO-bis(naphthalen-1-yl)-N,NO-bis(phenyl)- } \\
\text { benzidine (NPB) }\end{array}$ & 10 & 3.8 & 0.82 & 49 & 1.5 & 25 \\
\hline $\begin{array}{l}\text { 1,1-bis-(4-bis(4- methyl-phenyl)-amino- } \\
\text { phenyl)-cyclohexane (TAPC) }\end{array}$ & 5.0 & 5.94 & 0.91 & 52 & 2.8 & 20 \\
\hline Rubrene & 5.0 & 5.9 & 0.89 & - & - & 20 \\
\hline $\begin{array}{l}5,5^{\prime \prime \prime \prime}-\text { bis(naphth-2-yl)-2, } 2^{\prime}: 5^{\prime}, 2^{\prime \prime}: 5^{\prime \prime}, 2^{\prime \prime \prime}: 5^{\prime \prime \prime}, 2^{\prime \prime \prime \prime \prime}- \\
\text { quinquethiophene (NaT5) }\end{array}$ & 5.0 & 6.1 & 0.94 & - & - & 20 \\
\hline $\begin{array}{l}\text { Tris[4-(5- phenylthiophen-2-yl)phenyl]amine } \\
\text { (TPTPA) }\end{array}$ & 5 & 5.5 & 0.92 & 52 & 2.6 & 28 \\
\hline
\end{tabular}

donor concentrations generally range from $2 \%$ to $25 \%$. The differences in performance are most strongly related to the choice of donor and acceptor materials, as well as the thickness of the active layer; however, the choice of anode and cathode buffer layers, material purity and differences in fabrication process also play critical roles. Note that when values were not listed explicitly in table or text format, values were obtained from associated graphs/figures. For easier comparison, the reported performance figures for neat- $\mathrm{C}_{60}$ and neat- $\mathrm{C}_{70}$ Schottky OSCs were from the same research group.

Some highlights from Table 1 are addressed presently. Pandey et al. fabricated $\mathrm{C}_{60}$ and $\mathrm{C}_{70}$ Schottky OSCs with a boron subphthalocyanine (SubPc) donor material. ${ }^{26,31}$ While the researchers did not explicitly refer to the Schottky effect in their work, the $V_{o c}$ and $J_{s c}$ dependences on the mixing ratio follow the trends first reported by Zhang et al., i.e., the $\mathrm{V}_{\text {oc }}$ increases as SubPc concentration decreases and the $\mathrm{J}_{\mathrm{sc}}$ is at a maximum when the SubPc concentration is quite low at $20 \%{ }^{26}$ The optimum efficiency obtained with their SubPc: $\mathrm{C}_{60}$ Schottky OSC was found to be $3.7 \%$, whereas their SubPc: $\mathrm{C}_{70}$ Schottky OSC achieved an impressive $4.7 \%$. By using a graded doping profile, they further improved the efficiency of their SubPc: $\mathrm{C}_{60}$ devices to $4.5 \%$ and their SubPc: $\mathrm{C}_{70}$ devices to $5.4 \%{ }^{26,31,34}$ Figure 3(a) shows the doping profile of 
Table 2 Performance summary of $\mathrm{C}_{70}$-based Schottky OSCs reported in the literature.

\begin{tabular}{lcccccc}
\hline \hline Donor & $\begin{array}{c}\text { Donor } \\
\text { doping [\%] }\end{array}$ & $\begin{array}{c}\mathrm{J}_{\mathrm{sc}} \\
{\left[\mathrm{mAcm}^{-2}\right]}\end{array}$ & $\mathrm{V}_{\mathrm{oc}}[\mathrm{V}]$ & $\mathrm{FF}[\%]$ & PCE [\%] & References \\
\hline- & 0 & 1.4 & 1.3 & 34 & 0.58 & 25 \\
CIAIPc & 20 & 11.0 & 0.92 & 39 & 3.9 & 28 \\
SubPc & 5 & 9.5 & 1.11 & 37 & 3.9 & 30 \\
SubPc & 20 & 16 & 0.98 & 43 & 4.7 & 31 \\
Tetraphenyldibenzoperiflanthene (DBP) & 5 & 12.1 & 0.92 & 53 & 5.9 & 30 \\
DBP & 11.1 & 12.3 & 0.91 & 56 & 6.4 & 32 \\
DBP & 11.1 & 13.2 & 0.93 & 66 & 8.1 & 18 \\
$\begin{array}{l}\text { 2,4-bis[4-(N,N-diisobutylamino)-2,6- } \\
\text { dihydroxyphenyl] squaraine (DIB-SQ) }\end{array}$ & 16.7 & 13.6 & 0.86 & 52 & 6.1 & 33 \\
TAPC & 5 & 11.1 & 0.88 & 52 & 5.0 & 30 \\
TPTPA & 5 & 11.6 & 0.91 & 50 & 5.2 & 28 \\
\hline \hline
\end{tabular}

a graded SubPc: $\mathrm{C}_{70}$ device with an (overall) $80 \% \mathrm{C}_{70}$ concentration. Figure 3(b) compares the $\mathrm{I}-\mathrm{V}$ curves of planar junction, uniformly mixed and graded OSCs under $134 \mathrm{~mA} / \mathrm{cm}^{2}$ AM1.5G solar irradiation.

Chen et al. fabricated a 2,4-bis[4-(N,N-diisobutylamino)-2,6-dihydroxyphenyl] squaraine $\left(\right.$ DIB-SQ) $: \mathrm{C}_{70}$ OSCs with the device structure: ITO/ $\mathrm{MoO}_{3} /$ DIB-SQ: $\mathrm{C}_{70} /$ bathocuproine (BCP)/Al. ${ }^{33}$ The optimum performance was obtained for a DIB-SQ concentration of $16.7 \%$, which showed a PCE of $6.1 \%$, providing a $\mathrm{J}_{\mathrm{sc}}$ of $13.6 \mathrm{~mA} / \mathrm{cm}^{2}, \mathrm{~V}_{\mathrm{oc}}$ of $0.86 \mathrm{~V}$, and a $\mathrm{FF}$ of $52 \%$. The $\mathrm{V}_{\mathrm{oc}}$ of the cells increased from $0.77 \mathrm{~V}$ for $50 \%$ DIB-SQ to around $0.94 \mathrm{~V}$ for $4.8 \%$ DIB-SQ, as expected for a Schottky structure OSC. Surprisingly, a $\mathrm{J}_{\mathrm{sc}}$ of $10.4 \mathrm{~mA} / \mathrm{cm}^{2}$ was reported for this device even when the concentration of DIB-SQ was as low as $0.05 \%$, indicating that DIB-SQ is a well-suited donor material for the Schottky OSC configuration (primarily due to its energy levels, which is discussed in Sec. 3 of this review). Chen et al. also demonstrated solution processed OSCs with the device structure: ITO/ $\mathrm{MoO}_{3} /$ DIB-SQ: $\mathrm{PC}_{70} \mathrm{BM} / \mathrm{BCP} / \mathrm{Al}^{35}{ }^{35}$ Similar to the vacuum-deposited device, the best performance
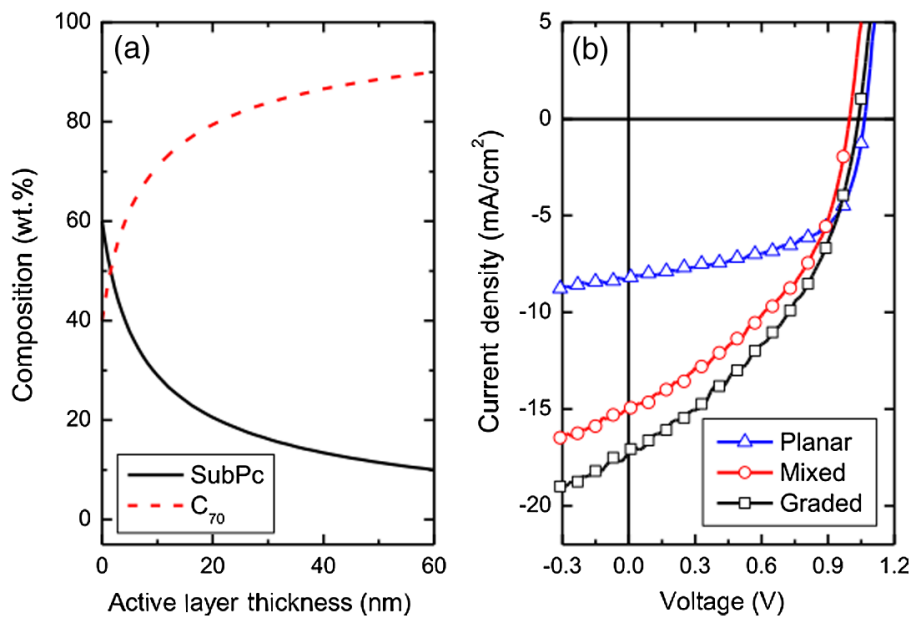

Fig. 3 (a) Graded doping profile of SubPc: $\mathrm{C}_{70}$ devices with an overall $\mathrm{C}_{70}$ concentration of $80 \%$ and (b) I-V curves under $134 \mathrm{~mA} / \mathrm{cm}^{2}$ AM1.5G irradiation for a planar junction device $(11 \mathrm{~nm}$ SubPc/35 $\mathrm{nm} \mathrm{C}_{70}$ ), a uniformly mixed $20 \%$ SubPc: $80 \% \mathrm{C}_{70}$ device and a graded $80 \% \mathrm{C}_{70}$ device. Reproduced with permission from Ref. 31. Copyright ( 2012 by American Institute of Physics. 
was attained for a DIB-SQ concentration of $16.7 \%$. The performance of the solution processed devices was lower, however, with a PCE of $4.0 \%, \mathrm{~J}_{\mathrm{sc}}$ of $10.6 \mathrm{~mA} / \mathrm{cm}^{2}, \mathrm{~V}_{\mathrm{oc}}$ of $0.93 \mathrm{~V}$, and FF of $41 \%$. OSCs fabricated with neat $\mathrm{PC}_{70} \mathrm{BM}$ showed a high $\mathrm{V}_{\mathrm{oc}}$ of $1.22 \mathrm{~V}$ but a very low $\mathrm{J}_{\mathrm{sc}}$ of only $0.2 \mathrm{~mA} / \mathrm{cm}^{2}$, indicating that the photogeneration of charge carriers is much less efficient than for Schottky OSCs that employ vacuum-deposited $\mathrm{C}_{70}$ films. The addition of 5\% DIB-SQ for the solution-processed $\left(\mathrm{PC}_{70} \mathrm{BM}\right)$ Schottky OSCs increased the $\mathrm{J}_{\mathrm{sc}}$ dramatically from 0.2 to $5.7 \mathrm{~mA} / \mathrm{cm}^{2}$, but decreased the $\mathrm{V}_{\text {oc }}$ to $0.95 \mathrm{~V}$. Intriguingly, further increasing the DIB-SQ concentration did not significantly affect the $\mathrm{V}_{\mathrm{oc}}$, which is contrary to the trends observed with vacuum-deposited Schottky OSCs.

Yang et al. demonstrated that the Schottky OSC architecture can be implemented using solution-processed $\mathrm{PC}_{70} \mathrm{BM}$ and polymer donor materials, such as poly(3-hexylthiophene) (P3HT), poly[4,8-bis-substituted-benzo[1,2-b:4,5-b'] dithiophene- 2,6-diyl-alt-4-substituted-thieno[3,4-

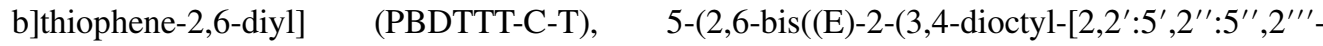
quaterthiophen]-5-yl)vinyl)-4H-pyran-4-ylidene)-1,3-diethyl-2-thioxodihydropyrimidine-4,6 (1H, 5H)-dione (8TPDC8), and fluorine-substituted poly[2,3-bis-(3-octyloxyphenyl) quinoxaline- 5,8diyl-alt-thiophene-2,5-diyl] (FTQ). ${ }^{36}$ They compared the performance of these materials in BHJ and Schottky OSCs. The concentration of donor material in the BHJ OSC was 50\%, whereas the concentration of donor material in the Schottky OSC was 5\%. Despite their varying HOMO and LUMO energy level offsets with $\mathrm{PC}_{70} \mathrm{BM}$, the $\mathrm{V}_{\mathrm{oc}}$ of the cells with the different donor materials remained constant at $0.85 \mathrm{~V}-0.87 \mathrm{~V}$ in the Schottky OSCs. The $\mathrm{V}_{\mathrm{oc}}$ was reflective of the $\mathrm{HOMO}_{\text {donor }}-\mathrm{LUMO}_{\text {acceptor }}$ energy level difference in BHJ OSCs. The efficiency of the P3HT:PC ${ }_{70} \mathrm{BM}$ Schottky OSC reached 3.3\%, with similar levels of performance from FTQ and PBDTTT-C-T donors. However, 8TPDC 8 was observed to have a very low FF and, consequently a lower efficiency. Yang et al. suggested that the donor material increases the dissociation efficiency of excitons with high binding energy in the fullerene material, whereas excitons with lower binding energy undergo field-assisted dissociation. This notion is discussed in further detail in Sec. 3 of this review.

Zhang et al. fabricated a Schottky junction tandem cell, ${ }^{37}$ with an active layer composed of TAPC: $\mathrm{C}_{60}$ with 5\% TAPC doping concentration. The tandem interlayer was composed of Ag and 1,4,5,8,9,11-hexaazatriphenylene hexacarbo-nitrile (HAT-CN). The optimized tandem cells showed a peak power conversion efficiency of $4.12 \%$ (double stack) and $4.42 \%$ (triple stack). The $\mathrm{V}_{\mathrm{oc}}$ values of the tandem Schottky cells were quite high with almost no loss due to the interlayers. The single cell showed a $\mathrm{V}_{\mathrm{oc}}$ of $0.91 \mathrm{~V}$, whereas the double and triple stacks showed $\mathrm{V}_{\mathrm{oc}}$ values of 1.81 and $2.71 \mathrm{~V}$, respectively. The $\mathrm{J}_{\mathrm{sc}}$, however, suffered from drastic reductions in the tandem configuration. The single cell showed a $\mathbf{J}_{\mathrm{sc}}$ of $6.77 \mathrm{~mA} / \mathrm{cm}^{2}$. In a double-stack configuration, the $\mathrm{J}_{\mathrm{sc}}$ decreased dramatically to $4.30 \mathrm{~mA} / \mathrm{cm}^{2}$, and the triple-stack $\mathrm{J}_{\mathrm{sc}}$ was further reduced to $3.08 \mathrm{~mA} / \mathrm{cm}^{2}$. Since the $\mathrm{FF}$ did not significantly change in the tandem configuration (approximately 53\%), the $\mathrm{J}_{\mathrm{sc}}$ losses can be attributed to reduced absorption in each subsequent cell of the tandem stack; $\mathrm{C}_{60}$ was the only absorbing species and it was used in each of the subcells. Since the Schottky architecture generally relies on strong fullerene photocurrents, and fullerene is essential to the Schottky OSC operation (i.e., it cannot be replaced with alternative acceptors with different absorption characteristics), the tandem cell approach is thus shown to be poorly suited for stacked Schottky OSCs in general. An individual Schottky OSC may, however, be reasonably successful as a single subcell within a tandem structure, where the other subcells employ standard BHJ structure OSCs.

In 2013, Xiao et. al and Zheng et al. reported on the use of tetraphenyldibenzoperiflanthene (DBP) as a donor material in $\mathrm{C}_{70}$ Schottky OSCs, demonstrating very high efficiencies. ${ }^{30,32}$ Using the structure ITO/ $\mathrm{MoO}_{3} / \mathrm{DBP}(11.1 \%): \mathrm{C}_{70} / \mathrm{BPhen} / \mathrm{Al}$, Xiao et al. achieved a PCE of $5.7 \%$ with a $\mathrm{J}_{\mathrm{sc}}$ of $10.7 \mathrm{~mA} / \mathrm{cm}^{2}, \mathrm{~V}_{\mathrm{oc}}$ of $0.90 \mathrm{~V}$, and $\mathrm{FF}$ of $57 \%$. By adding a thin $9-\mathrm{nm}$ layer of neat- $\mathrm{C}_{70}$ after the mixed DBP: $\mathrm{C}_{70}$ layer, the $\mathrm{J}_{\mathrm{sc}}$ increased to $12.3 \mathrm{~mA} / \mathrm{cm}^{2}$ allowing for a PCE of $6.4 \%$. The neat- $\mathrm{C}_{70}$ layer was suggested to shift the optical field maximum away from the ITO $/ \mathrm{MoO}_{3}$ anode resulting in reduced exciton quenching and consequently improved carrier generation. Zheng et al. similarly reported a PCE of $6.4 \%$ with the OSC structure: $\mathrm{ITO} / \mathrm{MoO}_{3} / \mathrm{DBP}(5 \%): \mathrm{C}_{70} / \mathrm{BCP} / \mathrm{Ag}$. Xiao et al. further improved their DBP: $\mathrm{C}_{70}$ Schottky OSC efficiencies to an impressive $8.1 \%$ by using a cathode buffer layer composed of BPhen: $\mathrm{C}_{60}(1: 1) / \mathrm{BPhen}^{18}$ The mixed buffer layer was noted to improve performance by 
selectively conducting electrons, while simultaneously reducing bimolecular recombination and exciton polaron quenching. The final device structure of their $8.1 \%$ PCE OSC was: ITO $/ \mathrm{MoO}_{3} / \mathrm{DBP}(11.1 \%): \mathrm{C}_{70} / \mathrm{C}_{70} / \mathrm{BPhen}(50 \%): \mathrm{C}_{60} / \mathrm{BPhen} / \mathrm{Ag}$.

Zheng et al. reported efficient $\mathrm{C}_{70}$-based Schottky OSCs using a tris[4-(5-phenylthiophen-2yl)phenyl]-amine (TPTPA) donor material. ${ }^{28}$ Using the structure $\mathrm{ITO} / \mathrm{MoO}_{3} /$ TPTPA $(5 \%): \mathrm{C}_{70} / \mathrm{BCP} / \mathrm{Ag}$, the OSCs showed a PCE of $5.23 \%$ with a $\mathrm{J}_{\mathrm{sc}}$ of $11.6 \mathrm{~mA} / \mathrm{cm}^{2}$, $\mathrm{V}_{\mathrm{oc}}$ of $0.91 \mathrm{~V}$, and $\mathrm{FF}$ of $49.6 \%$. Several different cathode buffer layers were employed to improve electron conduction to the cathode. A buffer layer composed of $5 \mathrm{~nm} \mathrm{3,4,9,10-}$ perylenetetracarboxylic bis-benzimidazole (PTCBI) $/ 5 \mathrm{~nm} \mathrm{BCP} \mathrm{was} \mathrm{found} \mathrm{to} \mathrm{increase} \mathrm{both}$ the $\mathrm{J}_{\mathrm{sc}}$ and FF compared to the standard 10-nm BCP buffer layer. As a result of the optimized buffer layer, the PCE of the TPTPA: $\mathrm{C}_{70}$ Schottky OSCs was shown to increase from $5.23 \%$ to $5.96 \%$.

\section{Further Insights into the Device Physics of Fullerene-Based Schottky Organic Solar Cells}

The origin of the high $\mathrm{V}_{\mathrm{oc}}$ in fullerene Schottky OSCs was explained thoroughly by Zhang et al. as being caused by CT and subsequent band bending at the ITO/ $\mathrm{MoO}_{3} /$ fullerene interface. ${ }^{19,21}$ Subsequent studies on the device physics of fullerene-based Schottky OSCs have focused on explaining the origin of $\mathrm{J}_{\mathrm{sc}}$, the role of the donor material, and the dynamics of charge transport. Zhang et al. suggested that the photocurrent produced by neat-fullerene Schottky devices (i.e., those without a donor dopant) was due to field-assisted exciton dissociation in the bulk fullerene film due to the work function difference between the $\mathrm{ITO} / \mathrm{MoO}_{3}$ anode and the $\mathrm{LiF} / \mathrm{Al}$ cathode. ${ }^{19}$ They observed that the photocurrent produced by these cells was linearly dependent on the applied voltage, indicating high levels of charge recombination within the device. Several groups have since observed the same phenomenon in neat-fullerene Schottky OSCs. ${ }^{30,36}$ Yang et al. suggested that a likely reason for high recombination in these devices was due to the extremely low hole mobility in neat-fullerene Schottky OSCs ${ }^{36}$ Based on a report by Kazaoui et al., ${ }^{38}$ they also suggested that the origin of the $\mathrm{J}_{\mathrm{sc}}$ in neat-fullerene Schottky OSCs was due to the dissociation of weakly bound excitons in the fullerene material.

Kazaoui et al. investigated the excitation relaxation processes and photocarrier generation mechanisms in both $\mathrm{C}_{60}$ and $\mathrm{C}_{70}$ films using $\mathrm{UV}$-visible absorption, electroabsorption, luminescence, electric-field-induced luminescence quenching, and steady-state photoconductivity experiments. ${ }^{38,39}$ Figure 4 shows the absorption spectrum, luminescence excitation spectrum, and luminescence efficiency spectrum of a 20 -nm-thick $\mathrm{C}_{60}$ film. ${ }^{38}$ In the absorption spectrum [Fig. 4(a)], the peak at $3.53 \mathrm{eV}$ (approximately $351 \mathrm{~nm}$ ) is common to both $\mathrm{C}_{60}$ in solution as well as $\mathrm{C}_{60}$ in the solid state (thin films). However, the wide absorption band stretching from

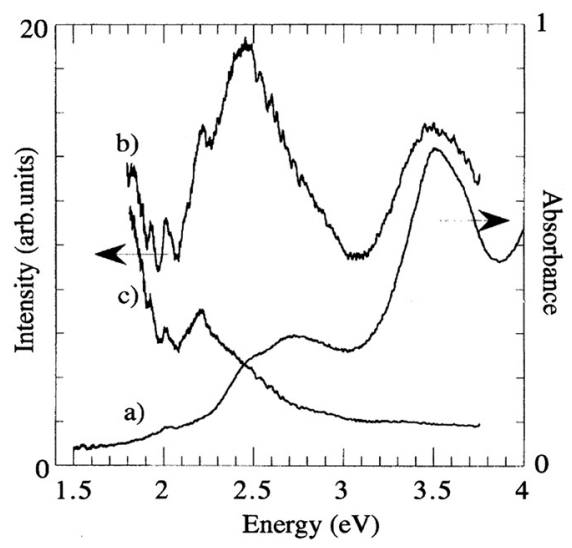

Fig. 4 (a) UV/visible absorption, (b) luminesence excitation (monitoring at $1.66 \mathrm{eV}$ ) and (c) luminescence efficiency spectra $\left(T=77 \mathrm{~K}\right.$, annealed $\mathrm{C}_{60}$ film, $\left.20 \mathrm{~nm}\right)$. Reproduced with permission from Ref. 38. Copyright (C) 1995 by the American Physical Society. 
approximately 2.3 to $3.0 \mathrm{eV}$ (approximately 539 to $413 \mathrm{~nm}$ ) is only found in thin films. Comparing the absorption, luminescence excitation spectra, and luminescence efficiency [Figs 4(b) and 4(c)], Kazaoui et al. concluded that the absorption peak at $3.53 \mathrm{eV}$ is due to the first allowed electronic transition in $\mathrm{C}_{60}$, leading to the formation of an intramolecular exciton. The feature between 2.3 and $3.0 \mathrm{eV}$ was attributed to interactions between neighboring $\mathrm{C}_{60}$ molecules, leading to the formation of an intermolecular CT exciton. ${ }^{38}$ Similar observations were also reported for $\mathrm{C}_{70}$ films. ${ }^{39}$

Kazaoui et al. also discussed the mechanism of dissociation of excitons in $\mathrm{C}_{60}$ as a multistep process $^{38}$ : (1) following the absorption of light, either an intramolecular exciton on an individual $\mathrm{C}_{60}$ molecule or intermolecular $\mathrm{CT}$ exciton between multiple $\mathrm{C}_{60}$ molecules is formed and (2) the exciton can either relax to the lowest singlet state by internal conversion, or it may form intermolecular CT states that can be dissociated into free carriers.

The dissociation process for excitons formed by light wavelengths from 330.6 to $539.1 \mathrm{~nm}$ was identified to be field assisted; however, excitons formed by light wavelengths from 539.1 to $729.3 \mathrm{~nm}$ required thermally assisted exciton dissociation due to their higher binding energies. Given the possibility for field-assisted exciton dissociation in neat-fullerene films, it is thus unsurprising that neat-fullerene Schottky OSCs show a strong voltage-dependent photocurrent. Furthermore, the FF for neat- $\mathrm{C}_{60}$ Schottky OSCs is quite low, with values usually below $35 \%$. Since the decay of excitons into singlet states competes with the formation of CT states that can be dissociated into charge carriers, a high level of recombination can be expected in neat- $\mathrm{C}_{60}$ Schottky OSCs, which consequently reduces FF.

Yang et al. conducted an extensive study comparing the external quantum efficiency (EQE) spectra of neat-PC ${ }_{70} \mathrm{BM}$ OSCs with $5 \%$ P3HT: $\mathrm{PC}_{70} \mathrm{BM}$ OSCs. ${ }^{36}$ The I-V curves of neat$\mathrm{PC}_{70} \mathrm{BM}$ OSCs and 5\% P3HT: $\mathrm{PC}_{70} \mathrm{BM}$ OSCs are shown in Fig. 5(a). The EQE spectra of neat $\mathrm{PC}_{70} \mathrm{BM}$ cells, shown in Fig. 5(b), exhibit photocurrent generation for wavelengths less than $540 \mathrm{~nm}$. We have reported similar observations with vaccum-deposited neat- $\mathrm{C}_{60}$ OSCs showing significant photocurrent generation for wavelengths below $540 \mathrm{~nm}$ [Fig. 6(a)]. ${ }^{25}$ Both results are in good agreement with previous work by Kazaoui et al., which confirms that the photocurrent generation efficiency of neat-fullerene films increases dramatically below $539.1 \mathrm{~nm}^{38}$

As noted previously, doping the neat-fullerene Schottky OSC with small concentrations of donor material results in a dramatic increase in photocurrent. ${ }^{20}$ Explicit comparisons of the EQE of neat-fullerene and donor-doped Schottky OSCs were first reported by Yang et al. with $\mathrm{P} 3 \mathrm{HT}: \mathrm{PC}_{70} \mathrm{BM}$, as shown in Fig. 5(b). ${ }^{36}$ Upon the addition of P3HT, the EQE is strongly enhanced across the entire spectrum. They attributed the EQE enhancement to an increase in the dissociation efficiency of both intramolecular and intermolecular excitons in $\mathrm{PC}_{70} \mathrm{BM}$ by charge transfer to P3HT donor. They also suggested that the P3HT donor material provided hole percolation pathways to the anode, and hence increased hole mobility (to potentially enhance FF) within the device.

In recent work, we performed a similar EQE study, but with vacuum-deposited chloroindium phthalocyanine $(\mathrm{ClInPc}): \mathrm{C}_{60}$ Schottky OSCs. ${ }^{25}$ We further included a $50 \%$ ClInPc: $\mathrm{C}_{60}$ Schottky OSC as a "standard BHJ structure" control. Figure 6(a) shows the EQE spectra
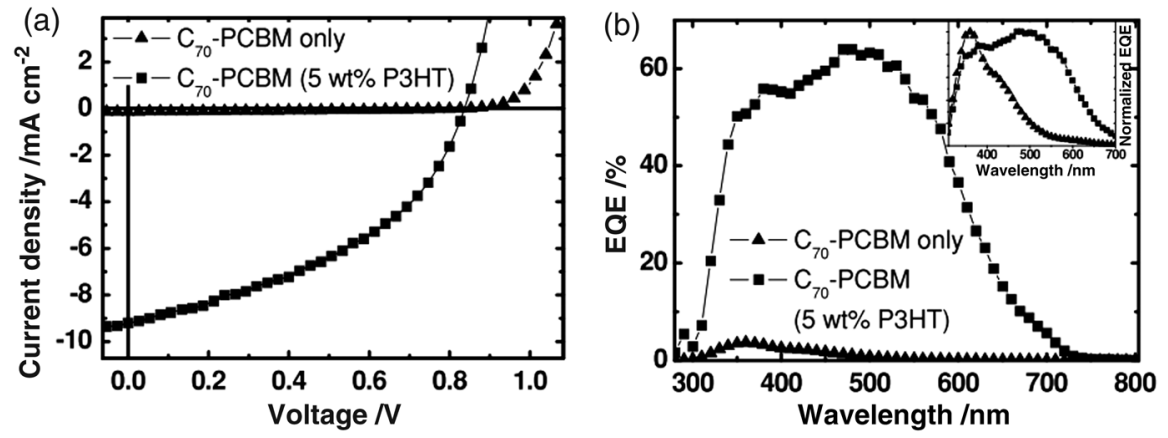

Fig. 5 (a) I-V curves and (b) EQE spectra of neat $\mathrm{PC}_{70} \mathrm{BM}$ and $5 \% \mathrm{P} 3 \mathrm{HT}: \mathrm{PC}_{70} \mathrm{BM}$ OSCs. Reproduced with permission from Ref. 36. Copyright (C 2012 by WILEY-VCH Verlag GmbH \& Co. 
(a)

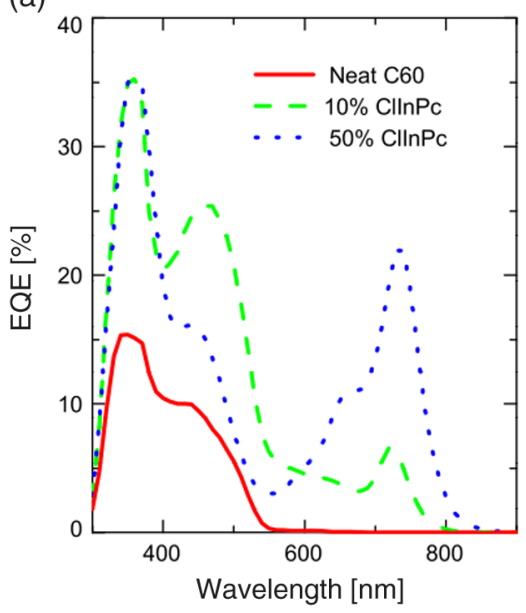

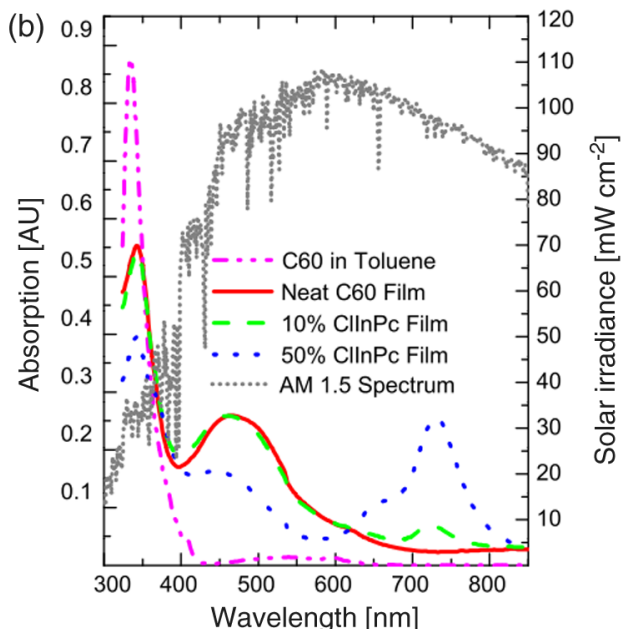

Fig. 6 (a) EQE spectra of ClInPc: $\mathrm{C}_{60}$ Schottky OSCs with varying ClInPc concentration and (b) UV/Vis absorption spectra of the same. Also shown: UV/Vis absorption spectrum of $\mathrm{C}_{60}$ and the AM1.5G spectrum. Reproduced with permission from Ref. 25. Copyright $\odot 2013$ by Elsevier B.V.

of ClInPc: $\mathrm{C}_{60}$ Schottky OSCs with varying donor concentration and Fig. 6(b) shows the UV/Vis absorption spectra of the same. Comparing the EQE and UV/Vis spectrum of the neat- $\mathrm{C}_{60}$ Schottky OSCs/films, it is clear that the shape of the EQE spectrum follows the absorption spectrum over the wavelengths 350 to $400 \mathrm{~nm}$, but it does not match for wavelengths 400 to $550 \mathrm{~nm}$. With the addition of $10 \%$ ClInPc to a neat- $\mathrm{C}_{60}$ Schottky OSC, we observed an increase in EQE across the entire spectrum, similar to the observations by Yang et al., indicating that the donor material increases the dissociation of both intramolecular and intermolecular excitons in $\mathrm{C}_{60}$ by $\mathrm{CT}$ to ClInPc. Furthermore, we noticed an enhancement in the EQE in the wavelength range from 400 to $550 \mathrm{~nm}$. As a result, the shape of the EQE spectra for the $10 \% \mathrm{ClInPc}_{\mathrm{C}} \mathrm{C}_{60}$ OSC follows the shape of the UV/Vis absorption of neat $C_{60}$ from $\lambda=400$ to $550 \mathrm{~nm}$ (thus suggesting that the donor is essential in harvesting these excitons, as is discussed further below). As the ClInPc doping concentration was increased to $50 \%$, the EQE in this region was again suppressed. The normalized EQE spectra indicate that this could not be explained by a reduction in the $\mathrm{C}_{60}$ concentration alone.

To better understand the photocurrent contributions from $\mathrm{C}_{60}$ in the wavelengths from 400 to $550 \mathrm{~nm}$, we examined the absorption spectrum of $\mathrm{C}_{60}$ in toluene [Fig. 6(b)]. Comparing the absorption spectra of $\mathrm{C}_{60}$ in toluene versus that of the neat the $\mathrm{C}_{60}$ film, the thin-film specific absorption band is clearly visible in the wavelength range of $\lambda=400 \mathrm{~nm}$ to $\lambda>600 \mathrm{~nm}$, with a peak at $\lambda=470 \mathrm{~nm}$. This absorption band was previously noticed by Kazaoui et al. and is suggested to be due to the aggregation of fullerene molecules in thin films. They also suggested that the absorption of light by fullerene in this wavelength range resulted in the formation of intermolecular CT excitons. ${ }^{38}$ Upon doping the $\mathrm{C}_{60}$ film with $10 \%$ CIInPc, the absorption of $\mathrm{C}_{60}$ at the $\lambda=350 \mathrm{~nm}$ band and $\lambda=470 \mathrm{~nm}$ band remain unchanged and a new band with a peak at $\lambda=720 \mathrm{~nm}$ corresponding to ClInPc absorption is observed. When the doping concentration of ClInPc is increased further to 50\%, the normalized UV/Vis absorption spectra show that the $\mathrm{C}_{60}$ intermolecular $\mathrm{CT}$ absorption band is preferentially suppressed, indicating that the aggregation of $\mathrm{C}_{60}$ molecules is hindered. ${ }^{25}$

Since the UV/Vis absorption spectra suggest strong changes in $\mathrm{C}_{60}$ aggregation behavior with varying concentrations of donor within the fullerene film, we studied the relevant films by atomic force microscopy (AFM). Figure 7 shows the AFM images of 50-nm $\mathrm{C}_{60}$ films with no ClInPc, $10 \%$ ClInPc, $20 \%$ ClInPc, and $50 \%$ ClInPc. Neat $\mathrm{C}_{60}$ films display a surface roughness of $3.3 \mathrm{~nm}$ with many nodules, which are indicative of aggregate formation. When $10 \% \mathrm{ClInPc}$ is doped in $\mathrm{C}_{60}$, the density of nodules appears unchanged and the surface roughness decreases slightly to $3.0 \mathrm{~nm}$. However, when $50 \%$ ClInPc is doped into the $\mathrm{C}_{60}$ film, the number of nodules is significantly diminished and the surface roughness decreases significantly 


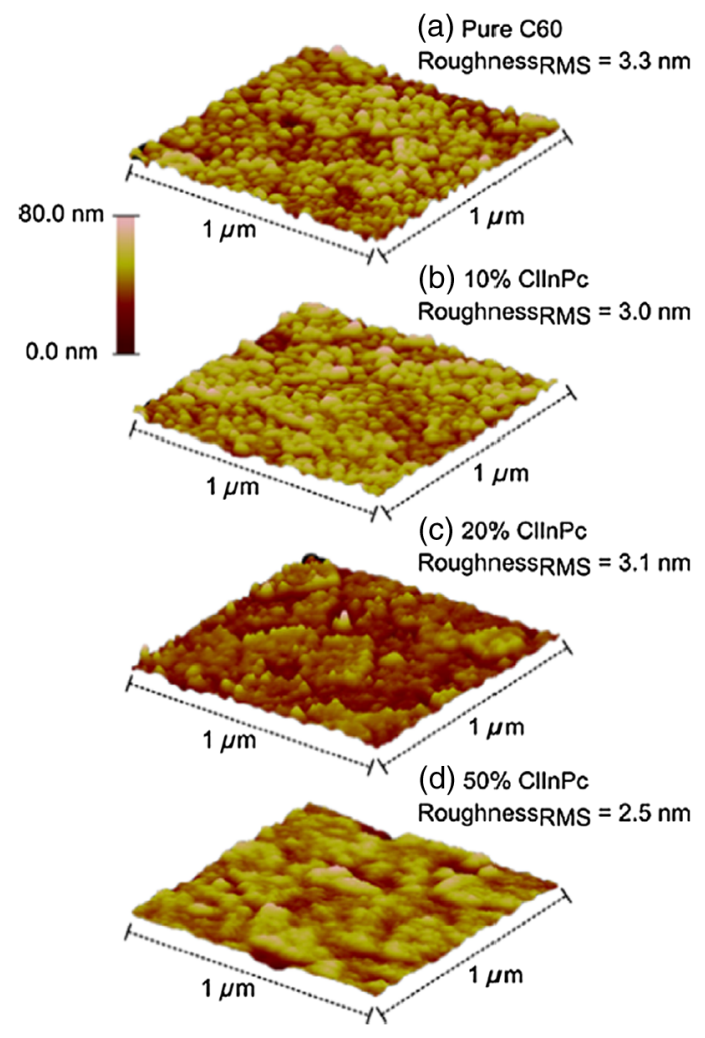

Fig. 7 AFM images of (a) neat $\mathrm{C}_{60}$ film, (b) $10 \%$ CllnPc in $\mathrm{C}_{60}$, (c) $20 \%$ CllnPc in $\mathrm{C}_{60}$, and (d) $50 \%$ CllnPc in $\mathrm{C}_{60}$. Reproduced with permission from Ref. 25. Copyright () 2013 by Elsevier B.V.

to $2.5 \mathrm{~nm}$. This is a strong indication for the reduction of $\mathrm{C}_{60}$ aggregates. Taking the UV/Vis absorption and AFM data together, it is evident that the aggregation of $\mathrm{C}_{60}$ molecules in thin films gives rise to the intermolecular CT absorption band from $\lambda=400$ to $600 \mathrm{~nm}$, confirming the previous stipulations by Kazaoui et al. ${ }^{25,38}$

Relating these observations to the EQE spectra of the devices, it can be seen that the reduction of $\mathrm{J}_{\mathrm{sc}}$ at high-donor doping concentrations is due to the reduction of the photocurrent generation by $\mathrm{C}_{60}$ aggregates. ${ }^{25}$ At high-donor doping concentrations, $\mathrm{C}_{60}$ aggregation is reduced, which leads to lower absorption in the $\mathrm{C}_{60}$ intermolecular $\mathrm{CT}$ absorption band from $\lambda=400$ to $600 \mathrm{~nm}$ and consequently, lower EQE over that wavelength range. The absorption (and associated photocurrent generation) by the donor material does not compensate for the loss of $\mathrm{C}_{60}$ aggregate absorption and, therefore, leads to an overall reduction of $\mathrm{J}_{\mathrm{sc}}$ of the solar cell. The reduction in $\mathbf{J}_{\mathrm{sc}}$ may also be associated with the generally poorer charge transport properties in films with lower $\mathrm{C}_{60}$ content. The optimum $\mathrm{J}_{\mathrm{sc}}$ generated by Schottky OSCs occurs when the donor doping increases exciton dissociation efficiency in the fullerene material without disrupting fullerene aggregation, which is also supported by later work by Zheng et al. ${ }^{40}$

The function of the donor material as an exciton dissociation agent has been investigated by Jin et al., and also in our previous work..$^{25,29}$ Since fullerenes are the primary light absorbers in Schottky OSCs, the dissociation of excitons from fullerene must proceed by hole transfer to the donor HOMO level from the fullerene HOMO level. By comparing the performance of Schottky OSCs comprising $\mathrm{C}_{60}$ films doped with various donor materials (NPB, CBP, m-MTDATA, $\mathrm{CuPc}$, and TCTA), Jin et al. observed that the optimum $\triangle \mathrm{HOMO}_{\text {donor-C60 }}$ energy level difference is approximately $0.8 \mathrm{eV}$. Figure 8 (a) shows a schematic of exciton dissociation in a $\mathrm{C}_{60}$ Schottky OSC. Figure 8(b) shows the optimum HOMO energy level difference required between a given donor and $\mathrm{C}_{60}$ to allow for efficient exciton dissociation, as determined empirically. Our results, which tested CBP, NPB, DCJTB, Alq3, and ClInPc donor materials, were in good agreement with the findings by Jin et al. ${ }^{25}$

Given the large disparity in donor and acceptor concentrations in Schottky structure OSCs, charge transport within these structures has naturally been studied at depth. ${ }^{20,25,26,28,33,40,41}$ Song 

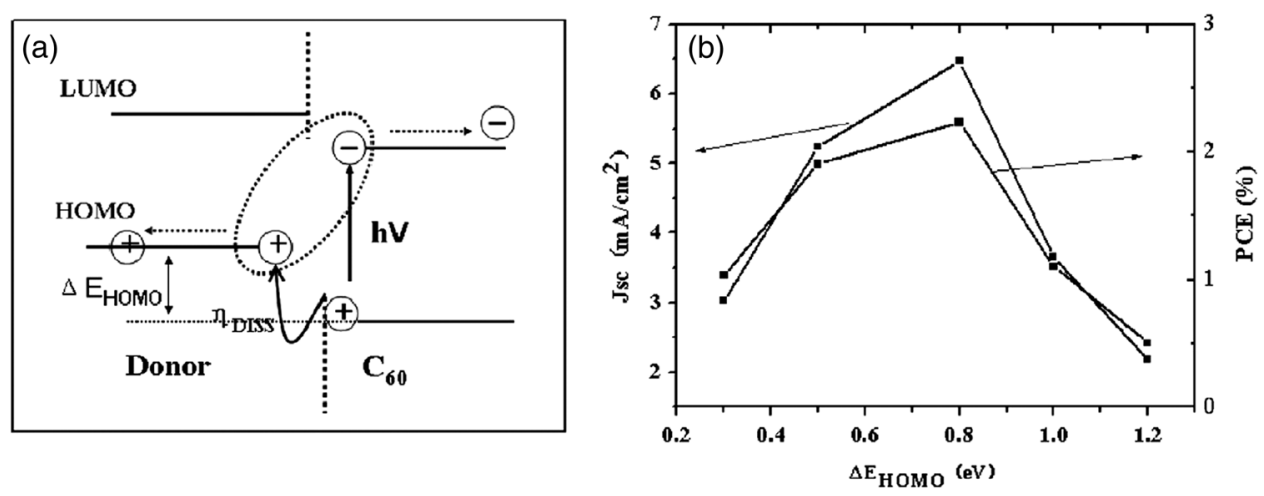

Fig. 8 (a) Schematic of exciton dissociation in a Schottky OSC doped with donor material and (b) optimal $\triangle \mathrm{HOMO}$ for $\mathrm{C}_{60}$ intermolecular $\mathrm{CT}$ exciton dissociation. Reproduced with permission from Ref. 29. Copyright $\odot 2013$ by Elsevier B.V.

et al. reported the temperature and light intensity dependences of the performance TAPC: $\mathrm{C}_{70}$ Schottky cells with varied TAPC doping levels. ${ }^{41}$ They observed that, for neat $\mathrm{C}_{70}$ and $10 \%$ TAPC: $\mathrm{C}_{70}$, monomolecular recombination dominated; however, for devices with $30 \%$ TAPC: $\mathrm{C}_{70}$, space-charge limited recombination was more likely. They also found that $30 \%$ TAPC $: \mathrm{C}_{70}$ cells had continuously increasing performance to $T=400 \mathrm{~K}$, indicating the release of trapped charges. Their measured electron and hole carrier mobilites showed that hole mobility was always two to three orders of magnitude lower than electron mobility, similar to observations noted by other researchers. ${ }^{20,26}$ Even when the donor concentration was $50 \%$, the hole mobility was found to be roughly an order of magnitude lower than the electron mobility. ${ }^{20,26}$ Further, the increase in hole mobility from 10\% TAPC to 30\% TAPC was not nearly as significant as the increase from 0\% TAPC to $10 \%$ TAPC. It is worth noting that the TAPC donor material absorbs in the UV wavelength range and, as a consequence, does not contribute to the photocurrent even in the $30 \%$ TAPC: $\mathrm{C}_{70}$ devices. It is likely that OSCs with donor materials that absorb in the visible range, and thus contribute to the photocurrent at high concentrations, could show different charge trapping and recombination behavior.

Several groups have determined that nanoscale phase separation of the donor material in vacuum-deposited small molecule films is more prevalent when the donor concentration is low. ${ }^{26,28,30,31}$ Using high-resolution transmission electron microscopy (TEM), Pandey et al. observed that the extensive phase separation is present in SubPc: $\mathrm{C}_{60}$ mixtures. ${ }^{26}$ Nanocrystalline domains of both SubPc and $\mathrm{C}_{60}$ were more prevalent in the $20 \%$ SubPc: $\mathrm{C}_{60}$ mixture than in the $50 \%$ SubPc: $\mathrm{C}_{60}$ mixture (which was completely amorphous), indicating that low donor concentration mixtures might be more prone to phase separation. Similar results were also demonstrated by Zheng et al. in TPTPA: $\mathrm{C}_{70}$ and DNTT: $\mathrm{C}_{70}$ Schottky OSCs at $5 \%$ donor concentration. ${ }^{28,40}$ Cross-sectional TEM images of $5 \%$ TPTPA: $\mathrm{C}_{70}$ OSCs are shown in Figs. 9(a) and 9(b). ${ }^{28}$ The black domains in Fig. 9(a) belong to TPTPA and white domains belong to $\mathrm{C}_{70}$, indicating clear phase separation between the two species. Both groups suggested that the phase separation was a likely cause for improved charge transport properties of low donor concentration active layers.

The spatial distribution of donor molecules within the donor: $\mathrm{C}_{70}$ mixed layer has been investigated by Zheng et al., and also in our previous work. ${ }^{24,25,30}$ Zheng et al. compared the performance of the following active layers: (A) $10 \mathrm{~nm} 5 \% \mathrm{DBP}: \mathrm{C}_{70} / 30 \mathrm{nmC}_{70}$ and (B) $30 \mathrm{~nm} \mathrm{C}_{70} / 10 \mathrm{~nm} 5 \% \mathrm{DBP}: \mathrm{C}_{70} \cdot{ }^{30}$ They found that the only $10 \mathrm{~nm}$ of $5 \% \mathrm{DBP}: \mathrm{C}_{70}$ was needed to greatly increase exciton dissociation, and hence the $\mathrm{J}_{\mathrm{sc}}$ in the entire active layer. They also found that the $\mathrm{FF}$ and $\mathrm{J}_{\mathrm{sc}}$ of the $30 \mathrm{~nm} \mathrm{C}_{70} / 10 \mathrm{~nm} 5 \% \mathrm{DBP}: \mathrm{C}_{70}$ structure (i.e., where the mixed layer is adjacent the cathode instead of the anode) was quite poor, indicating that the presence of donor is perhaps necessary for $\mathrm{CT}$ to the anode. To examine the extraction of holes in Schottky OSCs in more detail, we constructed CIInPc: $\mathrm{C}_{70}$ Schottky OSCs with an active layer structure: $10 \% \mathrm{CIInPc}: \mathrm{C}_{70}(x \mathrm{~nm}) / \mathrm{C}_{70}(30-x \mathrm{~nm})$. Increasing the thickness of the ClInPc: $\mathrm{C}_{70}$ layer increased the $\mathrm{J}_{\mathrm{sc}}$ due to better exciton dissociation but also degraded the FF due to poorer CT. As a result, the optimum $\mathrm{J}_{\mathrm{sc}}$, FF, and PCE were obtained when 

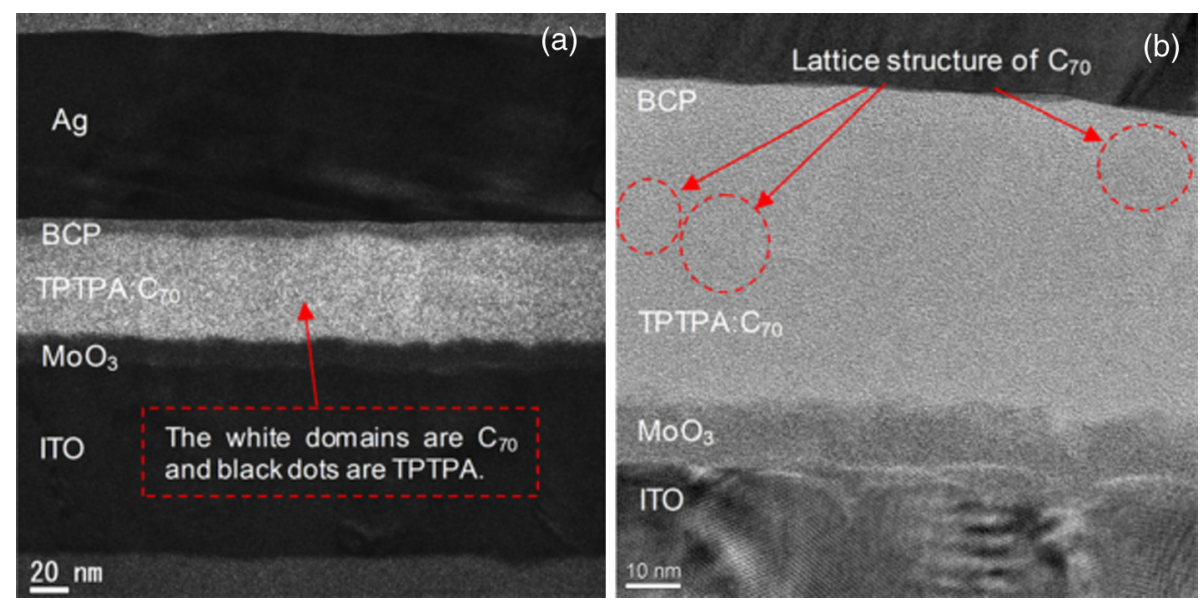

Fig. 9 (a) Energy-field mode and (b) bright-field mode cross-sectional TEM images of $5 \%$ TPTPA: $\mathrm{C}_{70}$ OSCs showing extensive phase separation between $\mathrm{C}_{70}$ and TPTPA. Reproduced with permission from Ref. 28. Copyright @ 2013 by American Institute of Physics.

the ClInPc: $\mathrm{C}_{70}$ thickness was $17.5 \mathrm{~nm}$ and the neat $\mathrm{C}_{70}$ thickness was $12.5 \mathrm{~nm}$. Considering these observations together, it is clear that the presence of a small amount of donor material at the anode is crucial to the performance of the Schottky OSC.

\section{Conclusions}

Fullerene-based Schottky OSCs have attracted considerable attention recently due to their simple structure and impressive performance. The key feature of fullerene-based Schottky OSCs is that the active layer is composed of a fullerene matrix doped with low concentrations of donor material and is placed next to a high work function anode. The high $\mathrm{V}_{\mathrm{oc}}$ of the fullerenebased Schottky OSC is now known to be due to the formation of an n-type Schottky junction at the high work function anode/fullerene interface. The, generally high $\mathrm{J}_{\mathrm{sc}}$ values obtained with this structure have been identified to be largely associated with fullerene aggregate absorption. Interestingly, the intermolecular excitons formed by fullerene aggregates are more strongly bound than the intramolecular excitons, and they require an added dissociation agent (beyond the built-in field) to generate free carriers. This is generally accomplished by doping the fullerene matrix with a small concentration of donor material, which increases the $\mathrm{J}_{\mathrm{sc}}$ and FF dramatically. However, if the donor concentration is too high, it disrupts the aggregation of fullerenes resulting in reduced $\mathbf{J}_{\mathrm{sc}}$ values. OSCs constructed with the Schottky junction architecture have been shown to reach efficiencies as high $8.1 \%$ in the literature, largely due to the use of donor materials with optimum energy levels for efficient exciton dissociation.

The main appeals of the fullerene-based Schottky OSC are its use of easily available materials, simple device structure, and very high power conversion efficiencies. It is shown to be capable of providing good performance with a much weaker dependence on the physical properties of the donor, as much of the OSC properties and associated photocurrent generations are provided by the fullerene. It could also be exciting to see fullerene-based Schottky OSCs used in tandem configurations with regular BHJ OSCs, which would allow for the absorption of a large portion of the solar spectrum. The development of fullerene-based Schottky OSCs has provided remarkable insights into the role of the fullerene material in driving OSC performance. The formation of the high work function anode/fullerene-based Schottky junction as well as the photoactive and CT properties of fullerene-rich active layers has been investigated in detail. Since fullerenes are currently the most popular acceptor materials in the field of organic photovoltaics, it is likely that these observations will be found applicable to any OSC that employs fullerene acceptors.

The broader impact of the development of fullerene-based Schottky OSCs is the realization of a novel alternative device structure that is capable of high PCEs. When evaluating the performance of a new donor material, this device architecture should be considered along with other 
more commonly studied OSC architectures, such as the standard BHJ and the p-i-n OSC. To this end, a good Schottky OSC donor has an optimum $\triangle \mathrm{HOMO}_{\text {donor-fullerene }}$ energy level offset with the fullerene acceptor and increases exciton dissociation efficiency without disrupting the aggregation of the fullerene material. As a consequence, the fullerene-based Schottky junction architecture is ideally suited for only specific donor materials, which may have drastically different properties than traditionally synthesized donor materials. With further optimization of the donor, the fullerene-based Schottky OSC architecture offers a simple, cost-effective method to achieving high-performance organic photovoltaics.

\section{Acknowledgments}

The authors would like to acknowledge financial support to this work from the Natural Sciences and Engineering Research Council of Canada (NSERC). SS acknowledges financial support through Ontario Graduate Scholarship and Waterloo Institute for Nanotechnology (WIN) Nanofellowship. GW acknowledges financial support through NSERC Alexander Graham Bell Canada Graduate Scholarship, Ontario Graduate Scholarship, and WIN Nanofellowship.

\section{References}

1. B. P. Rand et al., "Solar cells utilizing small molecular weight organic semiconductors," Prog. Photovolt: Res. Appl. 15(8), 659-676 (2007), http://dx.doi.org/10.1002/(ISSN) 1099-159X.

2. M. Riede et al., "Small-molecule solar cells-status and perspectives," Nanotechnology 19(42), 424001 (2008), http://dx.doi.org/10.1088/0957-4484/19/42/424001.

3. A. Mishra and P. Bäuerle, "Small molecule organic semiconductors on the move: promises for future solar energy technology," Angew. Chem. Int. Ed. Engl. 51(9), 2020-2067 (2012), http://dx.doi.org/10.1002/anie.201102326.

4. M. C. Scharber et al., "Design rules for donors in bulk-heterojunction solar cells-towards $10 \%$ energy-conversion efficiency," Adv. Mater. 18(6), 789-794 (2006), http://dx.doi.org/ 10.1002/(ISSN)1521-4095.

5. Y. Lin, Y. Li, and X. Zhan, "Small molecule semiconductors for high-efficiency organic photovoltaics," Chem. Soc. Rev. 41(11), 4245-4272 (2012), http://dx.doi.org/10.1039/ c2cs15313k.

6. G. A. Chamberlain, "Organic solar cells: a review," Sol. Cells 8(1), 47-83 (1983), http://dx .doi.org/10.1016/0379-6787(83)90039-X.

7. C. W. Tang, "Two-layer organic photovoltaic cell," Appl. Phys. Lett. 48(2), 183 (1986), http://dx.doi.org/10.1063/1.96937.

8. M. Hiramoto, H. Fujiwara, and M. Yokoyama, "Three-layered organic solar cell with a photoactive interlayer of codeposited pigments," Appl. Phys. Lett. 58(10), 1062 (1991), http://dx.doi.org/10.1063/1.104423.

9. P. Peumans, S. Uchida, and S. R. Forrest, "Efficient bulk heterojunction photovoltaic cells using small-molecular-weight organic thin films," Nature 425(6954), 158-162 (2003), http://dx.doi.org/10.1038/nature01949.

10. A. Sharenko et al., "A high-performing solution-processed small molecule:perylene diimide bulk heterojunction solar cell," Adv. Mater. 25(32), 4403-4406 (2013), http://dx.doi.org/10 .1002/adma.v25.32.

11. D. Gebeyehu et al., "Bulk-heterojunction photovoltaic devices based on donor-acceptor organic small molecule blends," Sol. Energy Mater. Sol. Cells 79(1), 81-92 (2003), http://dx.doi.org/10.1016/S0927-0248(02)00369-0.

12. G. Yu et al., "Polymer photovoltaic cells: enhanced efficiencies via a network of internal donor-acceptor heterojunctions," Science 270(5243), 1789-1791 (1995), http://dx.doi.org/ 10.1126/science.270.5243.1789.

13. P. Peumans and S. R. Forrest, "Very-high-efficiency double-heterostructure copper phthalocyanine $/ \mathrm{C}_{60}$ photovoltaic cells," Appl. Phys. Lett. 79(1), 126 (2001), http://dx .doi.org/10.1063/1.1384001. 
14. S. Yoo, B. Domercq, and B. Kippelen, "Efficient thin-film organic solar cells based on pentacene/C 60 heterojunctions," Appl. Phys. Lett. 85(22), 5427 (2004), http://dx.doi.org/ 10.1063/1.1829777.

15. B. Maennig et al., "Organic p-i-n solar cells," Appl. Phys. A. 79(1), 1-14 (2004), http://dx .doi.org/10.1007/s00339-003-2494-9.

16. M. Riede et al., "Efficient organic tandem solar cells based on small molecules," Adv. Funct. Mater. 21(16), 3019-3028 (2011), http://dx.doi.org/10.1002/adfm.201002760.

17. Heliatek, "Heliatek consolidates its technology leadership by establishing a new world record for organic solar technology with a cell efficiency of 12\%," http://www.heliatek.com/ newscenter/latest_news/neuer-weltrekord-fur-organische-solarzellen-heliatek-behauptet-sichmit-12-zelleffizienz-als-technologiefuhrer/?lang=en (28 February 2013).

18. X. Xiao et al., "Small-molecule planar-mixed heterojunction photovoltaic cells with fullerenebased electron filtering buffers," Adv. Energy Mater. 4(7), 1301557 (2013), http://dx.doi.org/ 10.1002/aenm.201301557.

19. M. Zhang et al., "Organic Schottky barrier photovoltaic cells based on $\mathrm{MoO}_{\mathrm{x}} / \mathrm{C}_{60}$," Appl. Phys. Lett. 96(18), 183301 (2010), http://dx.doi.org/10.1063/1.3415497.

20. M. Zhang et al., "Bulk heterojunction photovoltaic cells with low donor concentration," Adv. Mater. 23(42), 4960-4964 (2011), http://dx.doi.org/10.1002/adma.v23.42.

21. M. Zhang et al., "Strong interface p-doping and band bending in $\mathrm{C}_{60}$ on $\mathrm{MoO}_{\mathrm{x}}$," Org. Electron. 12(9), 1588-1593 (2011), http://dx.doi.org/10.1016/j.orgel.2011.06.007.

22. J. Widmer et al., "Open-circuit voltage and effective gap of organic solar cells," Adv. Funct. Mater. 23(46), 5814-5821 (2013), http://dx.doi.org/10.1002/adfm.v23.46.

23. M. L. Tietze et al., "Correlation of open-circuit voltage and energy levels in zinc-phthalocyanine: $\mathrm{C}_{60}$ bulk heterojunction solar cells with varied mixing ratio," Phys. Rev. B 88(8), 085119 (2013), http://dx.doi.org/10.1103/PhysRevB.88.085119.

24. S. Sutty, G. Williams, and H. Aziz, "New insights into charge extraction and formation of the band-bending region in Schottky junction organic solar cells," Proc. SPIE. 8830, 88300L (2013), http://dx.doi.org/10.1117/12.2023416.

25. S. Sutty, G. Williams, and H. Aziz, "Role of the donor material and the donor-acceptor mixing ratio in increasing the efficiency of Schottky junction organic solar cells," Org. Electron. 14(10), 2392-2400 (2013), http://dx.doi.org/10.1016/j.orgel.2013.06.001.

26. R. Pandey et al., "Efficient organic photovoltaic cells based on nanocrystalline mixtures of boron subphthalocyanine chloride and $\mathrm{C}_{60}$," Adv. Funct. Mater. 22(3), 617-624 (2012), http://dx.doi.org/10.1002/adfm.201101948.

27. G. Williams et al., "Renewed interest in metal phthalocyanine donors for small molecule organic solar cells,” Sol. Energy Mater. Sol. Cells 124, 217-226 (2014), http://dx.doi.org/10 .1016/j.solmat.2014.02.013.

28. Y. Zheng et al., "Highly efficient bulk heterojunction photovoltaic cell based on tris[4-(5phenylthiophen-2-yl)phenyl]amine and $\mathrm{C}_{70}$ combined with optimized electron transport layer," Appl. Phys. Lett. 102(15), 153302 (2013), http://dx.doi.org/10.1063/1.4801954.

29. F. Jin et al., "The influence of donor material on achieveing high photovoltaic response for organic bulk heterojunction cells with small ratio donor component," Org. Electron. 14(4), 1130-1135 (2013), http://dx.doi.org/10.1016/j.orgel.2013.01.026.

30. Y. Zheng et al., "Highly efficient bulk heterojunction photovoltaic cells based on $\mathrm{C}_{70}$ and tetraphenyldibenzoperiflanthene," Appl. Phys. Lett. 102(14), 143304 (2013), http://dx.doi .org/10.1063/1.4801647.

31. R. Pandey, Y. Zou, and R. J. Holmes, "Efficient, bulk heterojunction organic photovoltaic cells based on boron subphthalocyanine chloride-C ${ }_{70}, "$ Appl. Phys. Lett. 101(3), 033308 (2012), http://dx.doi.org/10.1063/1.4737902.

32. X. Xiao et al., "A hybrid planar-mixed tetraphenyldibenzoperiflanthene $/ \mathrm{C}_{70}$ photovoltaic cell," Appl. Phys. Lett. 102(7), 073302 (2013), http://dx.doi.org/10.1063/1.4793195.

33. G. Chen et al., "Co-evaporated bulk heterojunction solar cells with $>6.0 \%$ efficiency.," $A d v$. Mater. 24(20), 2768-2773 (2012), http://dx.doi.org/10.1002/adma.v24.20.

34. R. Pandey and R. J. Holmes, "Graded donor-acceptor heterojunctions for efficient organic photovoltaic cells," Adv. Mater. 22(46), 5301-5305 (2010), http://dx.doi.org/10.1002/adma .201002454 . 
35. G. Chen et al., "Solution-processed organic photovoltaic cells based on a squaraine dye," Phys. Chem. Chem. Phys. 14(42), 14661-14666 (2012), http://dx.doi.org/10.1039/ c2cp42445b.

36. B. Yang et al., "Solution-processed fullerene-based organic schottky junction devices for large-open-circuit-voltage organic solar cells," Adv. Mater. 25, 572-577 (2013), http://dx .doi.org/10.1002/adma.201203080.

37. M. Zhang, H. Wang, and C. W. Tang, "Tandem photovoltaic cells based on low-concentration donor doped C 60," Org. Electron. 13(2), 249-251 (2012), http://dx.doi.org/10 .1016/j.orgel.2011.11.004.

38. S. Kazaoui, R. Ross, and N. Minami, "Intermolecular charge-transfer excitation in $\mathrm{C}_{60}$ films: evidence from luminesence and photoconductivity," Phys. Rev. B 52(16), 4-7 (1995), http://dx.doi.org/10.1103/PhysRevB.52.R11665.

39. S. Kazaoui, N. Minami, and Y. Tanabe, "Comprehensive analysis of intermolecular chargetransfer excited states in C 60 and C 70 films," Phys. Rev. B 58(12), 7689-7700 (1998), http://dx.doi.org/10.1103/PhysRevB.58.7689.

40. Y. Zheng et al., "Comparison of small amounts of polycrystalline donor materials in $\mathrm{C}_{70^{-}}$ based bulk heterojunction photovoltaics and optimization of dinaphthothienothiophene based photovoltaic," Org. Electron. 15(4), 878-885 (2014), http://dx.doi.org/10.1016/j .orgel.2014.01.012.

41. H.-J. Song et al., "Origin of the mixing ratio dependence of power conversion efficiency in bulk heterojunction organic solar cells with low donor concentration," J. Nanosci. Nanotechnol. 13(12), 7982-7987 (2013), http://dx.doi.org/10.1166/jnn.2013.8155.

Sibi Sutty is a PhD degree candidate at the University of Waterloo, Canada. He received his bachelor's degree in applied science in nanotechnology engineering from the University of Waterloo in 2012. His current research is focused on understanding the influence of organic solar cell device architecture on performance. He has co-authored four manuscripts on the topic. In general, he is interested in research involving organic optoelectronic devices for display applications and energy harvesting. He is a member of SPIE.

Graeme Williams is a senior $\mathrm{PhD}$ student in Electrical and Computer Engineering at the University of Waterloo and a recipient of the NSERC Alexander Graham Bell Canada Graduate Scholarship. $\mathrm{He}$ is also a graduate of the first class of Nanotechnology Engineering (BASc) from the University of Waterloo. His research focuses on understanding novel organic photovoltaic structures, as well as elucidating factors that affect charge collection with time, specifically in consideration of organic-electrode interfacial degradation processes.

Hany Aziz is a professor in the Department of Electrical \& Computer Engineering, University of Waterloo, Canada. His research interests are in the area of organic electronic and optoelectronic materials and devices. He has published more than 100 papers (H-index 25) and holds 51 US patents. He received a $\mathrm{PhD}$ in Materials Science and Engineering from McMaster University in 1999. He was a research scientist at Xerox Research Centre of Canada in the period 1999-2007. 